\title{
An Economic Analysis of Ferric Derisomaltose versus Ferric Carboxymaltose in the Treatment of Iron Deficiency Anemia in Patients with Inflammatory Bowel Disease in Norway, Sweden, and Finland
}

This article was published in the following Dove Press journal:

ClinicoEconomics and Outcomes Research

\section{Richard F Pollock (D) \\ Gorden Muduma ${ }^{2}$}

'Health Economics and Outcomes Research, Covalence Research Ltd, London, UK; ${ }^{2}$ International Market Access, Pharmacosmos A/S, Holbæk, Denmark
Correspondence: Richard F Pollock Health Economics and Outcomes Research, Covalence Research Ltd, 5I Hayes Grove, London SE22 8DF, UK

Tel +442086386525

Email pollock@covalence-research.com
Background and Aims: Iron deficiency anemia (IDA) is a common sequela of inflammatory bowel disease (IBD), arising from the combined effects of gastrointestinal blood loss and reduced iron absorption. Given this, intravenous (IV) iron should be considered as the first-line treatment in patients with clinically active IBD. The present study evaluated the budget impact of administering IV iron with ferric derisomaltose (FDI) versus ferric carboxymaltose (FCM) in patients with IDA and IBD in Norway, Sweden, and Finland.

Methods: A cohort level model of iron need was developed using a bivariate distribution of hemoglobin and bodyweight based on observational data from a multi-country Scandinavian study of patients with IDA and IBD. The base case analysis was conducted over 5 years in patients with IDA with mean bodyweight of $75.4 \mathrm{~kg}$ (SD $17.5 \mathrm{~kg}$ ) and hemoglobin levels of $10.77 \mathrm{~g} / \mathrm{dL}$ (SD $1.43 \mathrm{~g} / \mathrm{dL}$ ). Infusion costs were modeled using diagnosis-related groups. Sensitivity analyses were performed around different patient characteristics, care settings, and retreatment frequencies, and probabilistic sensitivity analyses were conducted.

Results: Using FDI required 1.25 infusions to correct the mean iron deficit, compared with 1.64 infusions with FCM. In Norway, the per-patient cost of iron replenishment over 5 years was estimated to be NOK20,767 with FCM versus NOK15,799 with FDI, reflecting a cost saving of NOK4,968 or $23.9 \%$. In Finland, costs were projected to decrease from EUR3075 with FCM to EUR2339 with FDI, reflecting a cost saving of EUR736 per patient. In Sweden, costs decreased from SEK27,760 with FCM to SEK21,119 with FDI.

Conclusion: Using FDI in place of FCM resulted in a substantial reduction in the number of infusions required to correct iron deficits in patients with IDA and IBD. The reduction in infusions was accompanied by substantial cost savings relative to FCM over 5 years across all three Nordic countries evaluated.

Keywords: iron, administration, intravenous, iron deficiency anemia, inflammatory bowel diseases, Sweden, Norway, Finland

\section{Background and Aims}

Anemia is the most common extraintestinal manifestation of inflammatory bowel disease (IBD), with iron deficiency anemia (IDA) and anemia of chronic inflammation being the most common causes. ${ }^{1,2}$ Impaired intestinal iron absorption and ongoing blood loss are the primary mechanisms contributing to IDA in these patients. Iron supplementation is recommended in all patients with IBD when 
IDA is present, with the objective being to normalize hemoglobin levels and replenish iron stores. Absorption of iron from the gastrointestinal tract is limited in patients with IBD, and the European Crohn's and Colitis Organisation (ECCO) therefore recommends intravenous (IV) iron as the first-line treatment in patients with clinically active IBD, with previous intolerance to oral iron, with hemoglobin below $10 \mathrm{~g} / \mathrm{dL}$, and in patients who need erythropoiesis-stimulating agents (ESAs). ${ }^{1}$

Two high-dose, rapid-infusion IV iron formulations currently have marketing authorization in the European Union: ferric derisomaltose/iron isomaltoside 1000 (Monofer ${ }^{\circledR}$; Pharmacosmos A/S, Holbæk, Denmark; FDI) and ferric carboxymaltose $\left(\right.$ Ferinject ${ }^{\circledR}$; Vifor France, Paris, France; FCM). The formulations differ in the carbohydrate complexed with the iron and in the approved posology, with FDI able to be dosed up to $20 \mathrm{mg} / \mathrm{kg}$ bodyweight and FCM able to be dosed up to $20 \mathrm{mg} / \mathrm{kg}$ bodyweight but with an absolute dose ceiling of $1000 \mathrm{mg}$ regardless of bodyweight

To-date, only three randomized controlled trials (RCTs) have compared the formulations head-to-head: two RCTs comprising the PHOSPHARE program and the HOMe AFers 1 trial, all of which had primary endpoints pertaining to the incidence of hypophosphatemia after administration of IV iron. ${ }^{3,4}$ The two PHOSPHARE trials had identical study designs, and a pooled analysis of the results showed significantly lower incidence of hypophosphatemia $<2 \mathrm{mg} / \mathrm{dL}$ with FDI than FCM $(8.0 \%$ versus $74.4 \%, \mathrm{p}<0.0001)$, lower incidence of severe hypophosphatemia $(0.0 \%$ with FDI versus $11.3 \%$ with FCM, $\mathrm{p}<0.0001$, and lower incidence of serious or severe hypersensitivity reactions $(0.8 \%$ with FDI versus $1.7 \%$ with FCM). ${ }^{3}$ However, neither the PHOSPHARE nor HOMe AFers 1 RCTs included hematological response as a primary endpoint, and neither were conducted exclusively in patients with IBD. The applicability of the findings to patients with IBD and IDA is therefore uncertain, but a prospective 2019 observational study of 130 patients with IBD and IDA treated with the two formulations also reported a significantly higher incidence of overall and moderate-to-severe hypophosphatemia with FCM versus FDI at week 2 (72.5\% versus $11.3 \%$ for overall hypophosphatemia, $\mathrm{p}<0.001$, and $56.9 \%$ versus $5.7 \%$ for moderateto-severe hypophosphatemia, $\mathrm{p}<0.001){ }^{5}$

The only comparisons of hematological response with FDI and FCM in patients with IBD have been indirect. Two meta-analyses of hematological response in patients with IBD have been conducted; one frequentist pair-wise meta-analysis comparing the safety and efficacy of IV iron relative to oral iron and one Bayesian network metaanalysis comparing the efficacy of individual IV irons versus oral iron. ${ }^{6,7}$ The findings of both studies showed IV iron to be more efficacious than oral iron when considering a change from baseline hemoglobin of $\geq 2.0 \mathrm{~g} / \mathrm{dL}$. The latter study then further reported that there was no statistically significant difference in hematological response between the three IV iron formulations under investigation: FDI, FCM, and iron sucrose (IS). ${ }^{7}$ Given the lack of any significant difference in hematological response, the selection of the iron formulation should be guided by the adverse event profiles, and the resource use and economic implications of the differing posological characteristics of the two iron formulations.

Two previous economic evaluations of the IV irons have focused on patients with inflammatory bowel disease in the UK and Denmark, both showing cost savings with FDI relative to FCM. ${ }^{8,9}$ Given the high prevalence of IBD across the Nordic countries, the objective of the present study was to conduct a budget impact analysis of FDI versus FCM in the treatment of IDA in patients with IBD in Sweden, Norway, and Finland from the perspective of the national healthcare payers in the respective countries.

\section{Methods}

\section{Model Development}

A budget impact model was developed in Microsoft Excel (Microsoft Corporation, Redmond, WA) based on two interacting models: an iron need model, tailored to specific cohorts of patients with IDA and IBD in the Nordic countries, and an iron supply model to determine the number of iron infusions (and hence healthcare system interactions) required to address the iron need. The former iron need model was based on a bivariate distribution of bodyweight and hemoglobin combined with the iron need calculation approaches defined in the respective summaries of product characteristics (SPCs) for FDI and FCM: a simplified table of iron need or, in the case of FDI, the Ganzoni equation. The iron supply model was then developed to calculate the number of iron infusions needed to address the iron need across the whole cohort, based on dosing restrictions of $20 \mathrm{mg} / \mathrm{kg}$ bodyweight for both FDI and FCM, but with an absolute dose ceiling of $1000 \mathrm{mg}$ for FCM, as specified in the SPCs. 
Since IDA is commonly a chronic/recurrent condition in patients with IBD, the model also incorporated an iron retreatment frequency that was parameterized using data from a 2009 study published by Kulnigg et al in patients with IBD. ${ }^{10}$ Specifically, the study reported that anemia recurred in $50 \%$ of patients after 10 months $(95 \%$ confidence interval [CI] 8-12 months), while the median time until serum ferritin dropped to below $30 \mu \mathrm{g} / 1$ was 19 months (95\% CI 11-28 months). Iron retreatment was initiated after a median of 16 months (7-24 months). In the base case analysis, the median retreatment time of 16 months was used to model the retreatment frequency, with sensitivity analyses conducted around the times to recurrence of anemia and hypoferritinemia. Furthermore, in a probabilistic extension of the base case analysis, the $95 \%$ confidence intervals around the base case central estimate of 16 months were sampled in each arm independently to give an estimate of the effect of different retreatment frequencies on the budget impact.

\section{Patient Population}

Hemoglobin and bodyweight distributions were parameterized using data from a sub-group of the NIMO Scandinavian study, a prospective observational study including 149 patients with IDA and either Crohn's disease $(n=82)$ or ulcerative colitis $(n=67) .{ }^{11}$ Specifically, the mean hemoglobin at baseline was taken to be $10.77 \mathrm{~g} / \mathrm{dL}$ with a standard deviation of $1.43 \mathrm{~g} / \mathrm{dL}$, while mean bodyweight was assumed to be $75.40 \mathrm{~kg}$ with a standard deviation of $17.4 \mathrm{~kg}$. In the base case analysis, the hemoglobin distribution was modeled lognormally (Figure 1), with the mean and standard deviation parameters derived from the NIMO population on a logarithmic scale as follows:

$$
\begin{gathered}
H b \sim \ln \mathcal{N}(H b ; \mu, \sigma) \\
\mu=\ln \left(\frac{\mu_{H b}{ }^{2}}{\sqrt{\mu_{H b}{ }^{2}+\sigma_{H b}^{2}}}\right) \\
\sigma=\sqrt{\ln \left(\frac{\left(\mu_{H b}^{2}+\sigma_{H b}{ }^{2}\right)}{\mu_{H b}{ }^{2}}\right)}
\end{gathered}
$$

The bodyweight distribution was also modeled based on an underlying lognormal distribution (Figure 1), but also capturing a minimum bodyweight $\left(\mathrm{w}_{\min }\right)$ of $50 \mathrm{~kg}$. To avoid simply truncating the distribution at $50 \mathrm{~kg}$, the model mirrored the probability density function (PDF) around $\mathrm{w}_{\mathrm{min}}$, summing the reflected PDF below $\mathrm{w}_{\text {min }}$ with the PDF above $\mathrm{w}_{\min }$ as previously published: ${ }^{8}$

$$
\begin{aligned}
w & \sim \ln \mathcal{N}\left(w ; \mu, \sigma^{2}, w_{\text {min }}\right) \\
= & \left\{\begin{array}{cc}
0, & w<w_{\text {min }} \\
\ln N\left(w ; \mu, \sigma^{2}\right)+\ln N\left(2 w_{\text {min }}-w ; \mu, \sigma^{2}\right), & w \geq w_{\text {min }}
\end{array}\right.
\end{aligned}
$$

The total number of patients with IBD and IDA in the three countries was also estimated based on a top-down patient funnel approach, starting with 2021 estimates of the populations of Finland, Sweden, and Norway, multiplying by country-specific estimates of IBD prevalence in each country, and then by estimates of the proportion of patients with IBD with any form of anemia, and in turn the proportion of those patients who are also iron deficient. The IBD prevalence estimates for each country were obtained from the literature and combined with current estimates of the overall population in each country from the relevant national statistics authority. ${ }^{12-14}$ In

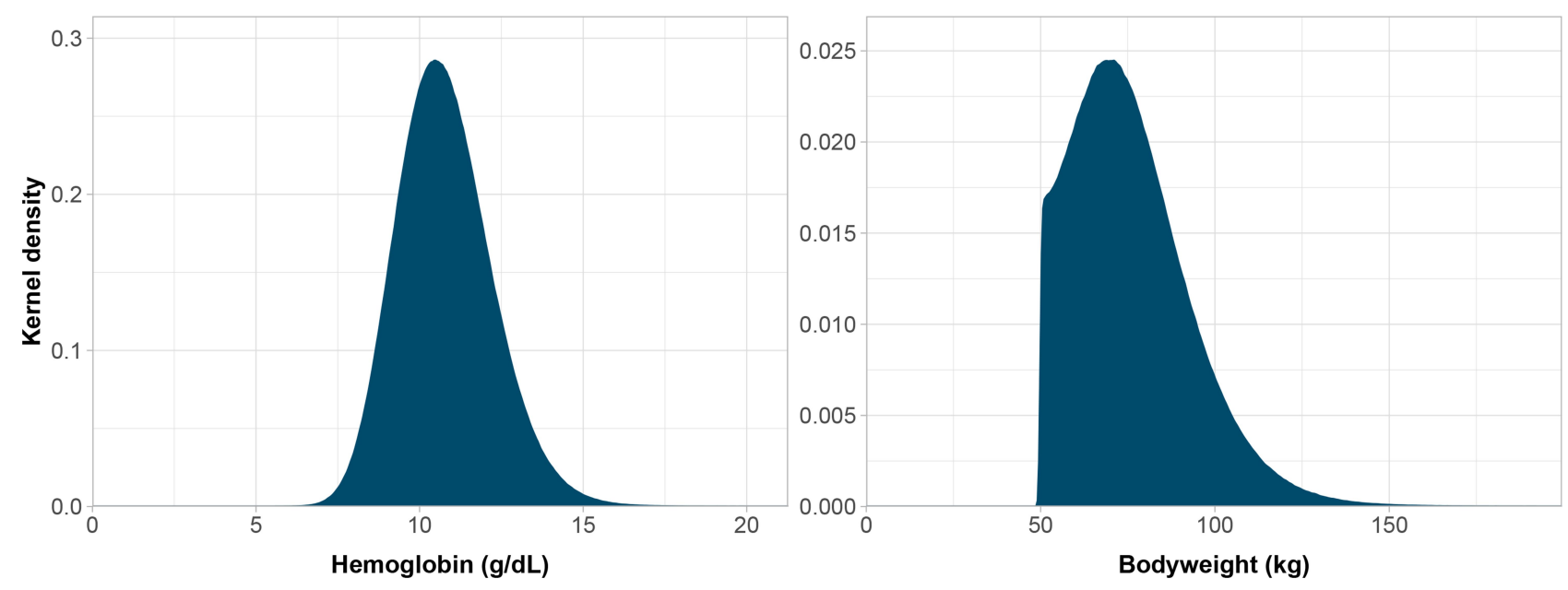

Figure I Bodyweight and hemoglobin distributions. 
a 2014 systematic literature review, Filmann et al reported that, in a heterogeneous population of 2192 patients with IBD across eight European countries (including Norway and Sweden), 24\% of patients with IBD had anemia of any form, and that, of those, $57 \%$ also had iron deficiency. ${ }^{15}$ These values were applied to the country-level prevalence estimates of IBD to give an estimate of the absolute number of patients with IBD and IDA in each of the three countries, and the budget impact of using FDI versus FCM estimated at the country level.

Data on time to retreatment from Kulnigg et al and on patient bodyweight and hemoglobin distributions from the NIMO Scandinavian study were taken from the published literature; no review or approval was therefore required by an institutional review board or ethics committee for their use in the present study.

\section{Perspective, Time Horizon, and Discounting}

All analyses were conducted from the perspective of the national healthcare payer, capturing direct medical costs only. A time horizon of 5 years was adopted in the base case analysis and explored in sensitivity analyses. Future costs were not discounted in line with the International Society for Pharmacoeconomics and Outcomes Research (ISPOR) principles of good practice for budget impact analysis, on the basis that budget holders are typically concerned with the budget impact at each point in time rather than a net present value. ${ }^{16}$

\section{Costs}

The cost per IV iron infusion was based on outpatient diagnosis-related groups (DRGs) specific to each of the three country settings. In Finland, DRG 9160 was used corresponding to the outpatient tariff for "Hematologia, lyhyt hoito ilman merkittävää toimenpidettä" or "Disease or disorder of blood forming organs or immunological disorder, short therapy w/o significant procedure" in line with advice from FCG Consulting Ltd., the certified developers of the NordDRG 2019 Grouper for Finland. This DRG was in turn based on the ICD-10 diagnosis code for D50.9 for "Iron deficiency anemia, unspecified". A representative 2019 tariff value of EUR 468 from the Kuopio University Hospital tariff list was employed in the base case analysis, selected as the median value of the publicly available tariffs identified for DRG 9160. ${ }^{17}$
In Sweden, DRG F89O "läkemedelstillförsel intravasalt vid sjukdomar i matsmältningsorganen, öppenvård" (outpatient intravascular drug delivery for gastrointestinal diseases) was used in the base case analysis, based on the assumption that a bowel specialist nurse would perform the iron infusion and that patients would have IBD as the primary diagnosis (ICD-10 codes K50 or K51), with IDA as a secondary diagnosis (ICD-10 code D50.8). DRG F89O was chosen conservatively as the base case tariff in Sweden, with a tariff weight of 0.069 , yielding a per-infusion cost of SEK 4225.08 based on the 2020 DRG reference weight of SEK 61233. The alternative DRG X70O "läkemedelstillförsel intravasalt, öppenvård" (outpatient intravenous medical treatment) was reserved for sensitivity analyses, as the current tariff weight of 0.081 resulted in a less conservative cost per infusion of SEK 4959.06. Both the base case and sensitivity analysis tariffs were confirmed through correspondence with the Classifications and Terminology Unit of the Socialstyrelsen in May 2020.

In Norway, the DRG tariff value in the base case analysis was obtained from the Norwegian DRG grouper using the 2020 DRGP definitions and ICD-10 code K50.9 ("Crohn's disease, unspecified") as the primary diagnosis, D50.8 ("Other iron deficiency anemias") as the secondary diagnosis, and Anatomical Therapeutic Chemical (ATC) classification code B03AC ("Iron, parenteral preparations") as the procedure code. The DRG basis point value for the resulting DRG code 906B was 0.069 , yielding a per-infusion cost of NOK 3160.75 based on the 2020 DRG point unit price of NOK $45808 .^{18}$

\section{Sensitivity Analyses}

A series of sensitivity analyses were conducted to test the robustness of the model results to changes in individual model parameters. Analyses were conducted around the mean bodyweight and hemoglobin parameters, specifically adopting a normal distribution rather than the lognormal distribution in the base case, varying the mean baseline bodyweight by $\pm 5 \mathrm{~kg}$, and varying the mean baseline hemoglobin by $\pm 1 \mathrm{~g} / \mathrm{dL}$. An alternative approach to the calculation of iron need was also employed by switching to the Ganzoni equation rather than the simplified tables of iron need from the SPCs. Finally, the IDA retreatment frequency was changed from 16 months in the base case to 10 months based on the time to recurrence of anemia, and 19 months based on the time to hypoferritinemia. ${ }^{10}$ 
Table I Base Case Analysis Results in Finland, Sweden, and Norway Over Five Years

\begin{tabular}{|c|c|c|c|c|c|c|c|c|c|}
\hline & \multicolumn{3}{|c|}{ Finland $(n=3 \mid 37)$} & \multicolumn{3}{|c|}{ Norway $(n=3 \mid 94)$} & \multicolumn{3}{|c|}{ Sweden $(n=9 \mid 93)$} \\
\hline & $\begin{array}{l}\text { FCM } \\
\text { Cost } \\
\text { (EUR) }\end{array}$ & $\begin{array}{l}\text { FDI } \\
\text { Cost } \\
\text { (EUR) }\end{array}$ & $\begin{array}{l}\text { Difference } \\
\text { (EUR) }\end{array}$ & $\begin{array}{l}\text { FCM } \\
\text { Cost } \\
\text { (NOK) }\end{array}$ & $\begin{array}{l}\text { FDI Cost } \\
\text { (NOK) }\end{array}$ & $\begin{array}{l}\text { Difference } \\
\text { (NOK) }\end{array}$ & $\begin{array}{l}\text { FCM } \\
\text { Cost } \\
\text { (SEK) }\end{array}$ & $\begin{array}{l}\text { FDI } \\
\text { Cost } \\
\text { (SEK) }\end{array}$ & $\begin{array}{l}\text { Difference } \\
\text { (SEK) }\end{array}$ \\
\hline Per patient & 3075 & 2339 & -736 & 20,767 & 15,799 & -4968 & 27,760 & 21,119 & $-664 \mid$ \\
\hline Whole country & $9.65 \mathrm{~m}$ & $7.34 \mathrm{~m}$ & $-2.3 \mathrm{Im}$ & $66.33 \mathrm{~m}$ & $50.46 \mathrm{~m}$ & $-15.87 \mathrm{~m}$ & $255.20 \mathrm{~m}$ & $194.15 \mathrm{~m}$ & $-61.05 m$ \\
\hline
\end{tabular}

Abbreviations: $\mathrm{Cl}$, confidence interval; FCM, ferric carboxymaltose; FDI, ferric derisomaltose; IS iron sucrose.

\section{Results}

Relative to FCM, FDI was found to be cost saving across all three country settings (Table 1). Costs of iron treatment per patient over 5 years reduced from EUR 3075 to EUR 2339 in Finland (saving EUR 736), from NOK 20,767 to NOK 15,799 in Norway (saving NOK 4968), and from SEK 27,760 to SEK 21,119 in Sweden (saving SEK 6641). As the cohort characteristics and posological constraints of the two iron formulations were assumed to be equivalent across the three countries, the relative cost reduction was $23.9 \%$ in all three country settings, based on an average 5.00 infusions per patient with FDI compared with 6.57 infusions per patient with FCM over 5 years, averaging an additional 1.57 infusions per patient with FCM. For each iron correction treatment, one iron infusion would be avoided for every
2.54 patients treated with FDI in place of FCM, and for a given infusion service with fixed capacity, for every 100 patients treated with FDI, only 76.1 patients with equivalent iron needs could be treated with FCM. Reductions in the number of iron infusions required with FDI versus FCM were realized in patients weighing $>75 \mathrm{~kg}$. In a cohort of 1000 patients, modeling the mean number of infusions required in each $1 \mathrm{~kg}$ bodyweight bin from 50 to $150 \mathrm{~kg}$ showed that the majority of the area between the curves for the respective iron formulations occurred in patients weighing $>75 \mathrm{~kg}$ (Figure 2). Furthermore, three discontinuities in the FDI distribution were apparent (Figure 2), corresponding to bodyweight thresholds at which the simplified tables of iron need in the SPCs recommend a higher iron dose for patients with hemoglobin $<14 \mathrm{~g} / \mathrm{dL}(70 \mathrm{~kg})$, at which FDI

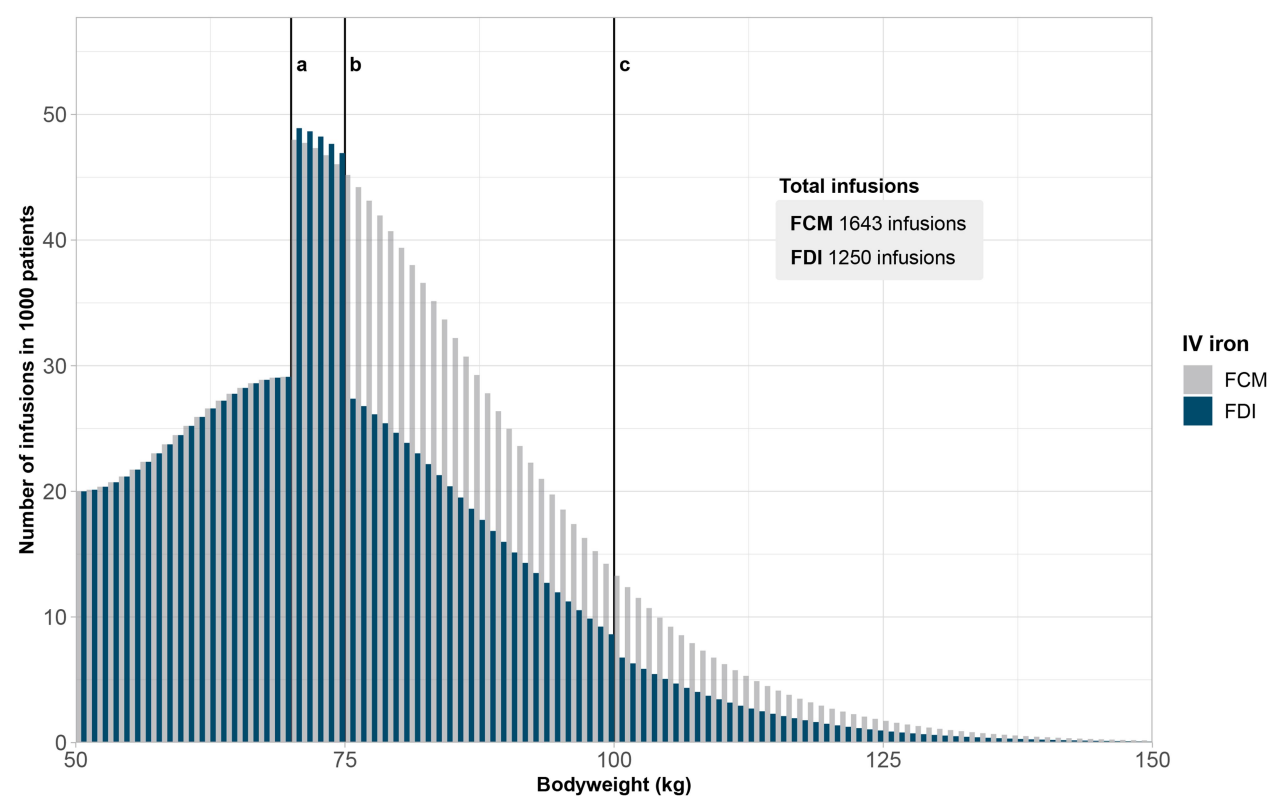

Figure 2 Mean number of infusions per year by bodyweight in a cohort of 1000 patients.

Notes: Analysis based on mean hemoglobin of $10.77 \mathrm{~g} / \mathrm{dL}$ and standard deviation of $1.43 \mathrm{~g} / \mathrm{dL}$. (a) $70 \mathrm{~kg}$, above which the simplified tables of iron need in the summaries of product characteristics specify an iron need of $2000 \mathrm{mg}$ in patients with hemoglobin $<10 \mathrm{~g} / \mathrm{dL}$ and $1500 \mathrm{mg}$ in patients with hemoglobin $\geq 10 \mathrm{~g} / \mathrm{dL}$ (or $500 \mathrm{mg}$ in patients treated with ferric carboxymaltose with hemoglobin $\geq 14 \mathrm{~g} / \mathrm{dL}$ ). (b) $75 \mathrm{~kg}$, at which patients receiving ferric derisomaltose can receive $1500 \mathrm{mg}$ of iron in a single infusion. (c) $100 \mathrm{~kg}$, at which patients receiving ferric derisomaltose can receive $2000 \mathrm{mg}$ of iron in a single infusion.

Abbreviations: FCM, ferric carboxymaltose; FDI, ferric derisomaltose. 
can be dosed at $1500 \mathrm{mg}(75 \mathrm{~kg})$, and at which FDI can be dosed at $2000 \mathrm{mg}(100 \mathrm{~kg})$.

In the probabilistic extension of the base case incorporating sampling around the duration between iron retreatments, the mean ( \pm standard deviation) cost estimates over 5 years were EUR 3326 (EUR \pm 657 ) with FCM versus EUR 2536 (EUR \pm 408 ) with FDI in Finland, NOK 22,907 (NOK \pm 4477 ) with FCM versus NOK 17,603 (NOK \pm 2519$)$ with FDI in Norway, and SEK 30,285 (SEK \pm 5681) with FCM versus SEK 23,049 $(\mathrm{SEK} \pm 3935)$ in Sweden (Figure 3).

The patient funnel approach to estimating the number of patients with IBD and IDA in each of the three countries provided estimates of 3137 in Finland, 3194 in Norway, and 9163 in Sweden (Figure 4). Analyses of the budget impact of using FDI in place of FCM at a country level showed projected savings of EUR $2.31 \mathrm{~m}$ over 5 years in Finland, NOK $15.87 \mathrm{~m}$ in Norway, and SEK $61.05 \mathrm{~m}$ in Sweden, based on the avoidance of 4931 infusions, 5020 infusions, and 14,450 infusions with FDI versus FCM in Finland, Norway, and Sweden, respectively, over 5 years.

One-way sensitivity analyses showed that the model was broadly insensitive to changes in individual input parameters, with no changes to the directionality of the results in any of the analyses conducted (Table 2), which covered the analysis time horizon, iron need calculation approach, patient characteristics, and retreatment frequency. The largest difference in incremental cost were observed over the 1 year time horizon, while other important drivers of cost differences were the mean bodyweight and hemoglobin assumptions, with reductions of $5 \mathrm{~kg}$ and $1 \mathrm{~g} / \mathrm{dL}$ reducing the cost savings with FDI from $23.9 \%$ in the base case to $19.2 \%$ and $16.7 \%$, respectively.

\section{Discussion}

The present analysis showed FDI to be cost-saving relative to FCM in the treatment of patients with IBD and IDA across all three Nordic countries included in the analysis. The cost savings were driven by a reduction in the number of infusions required with FDI relative to FCM, owing to the different dosing restrictions of the two iron formulations, namely the ability to infuse more than $1000 \mathrm{mg}$ of FDI in patients weighing more than $50 \mathrm{~kg}$. In patients for whom the established iron need is more than $1000 \mathrm{mg}$, this may allow the iron need to be addressed in a single infusion of FDI, in contrast to treatment with FCM, which has a maximum dose of $1000 \mathrm{mg}$ per infusion.

The modeling analysis had a number of strengths, including the use of cohort data specifically from patients in Scandinavia, the use of iron need calculation models exactly in line with the respective SPCs for FDI and FCM, and the use of national tariff values confirmed with the respective authorities on DRG coding in each of the three countries under investigation. The model outputs were also insensitive to changes in numerous input parameters in one-way sensitivity analyses. Furthermore, the modeling approach and a previously published modeling analysis conducted in IBD patients the UK setting have been corroborated by a recent retrospective analysis of data from 91 patients with IBD and either IDA or hypoferritenemia
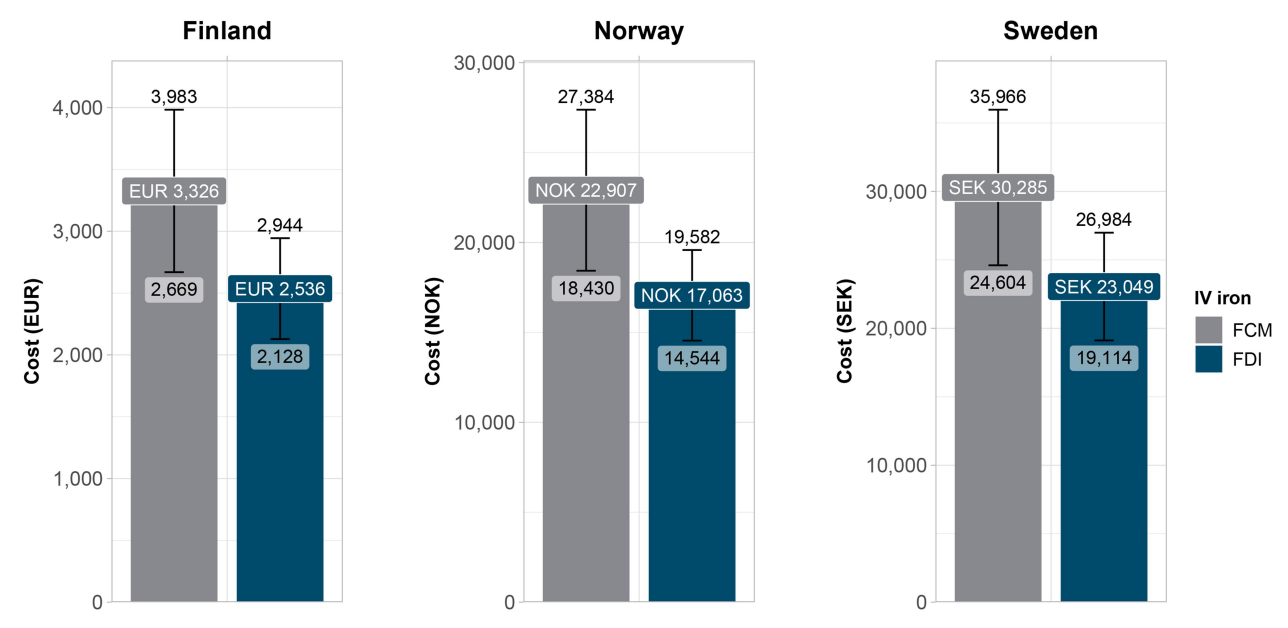

Figure 3 Probabilistic analysis of five-year costs of IV iron infusions with ferric carboxymaltose and ferric derisomaltose in patients with inflammatory bowel disease and iron deficiency anemia in Finland, Norway, and Sweden.

Note: Error bars show mean \pm standard deviation.

Abbreviations: EUR, euros; FCM, ferric carboxymaltose; FDI, ferric deriosmaltose; NOK, Norwegian krone; SEK, Swedish krona. 


\section{A}

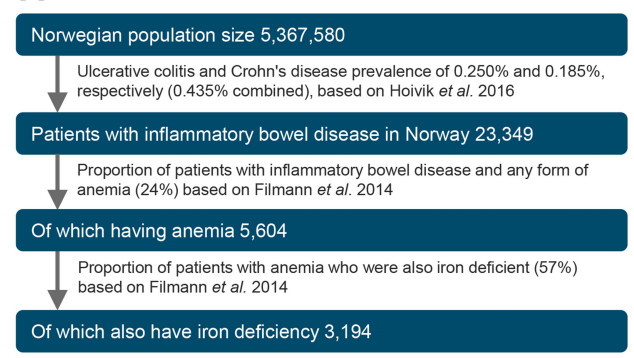

C

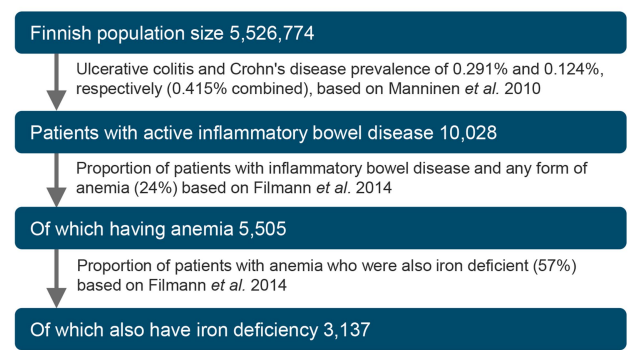

B

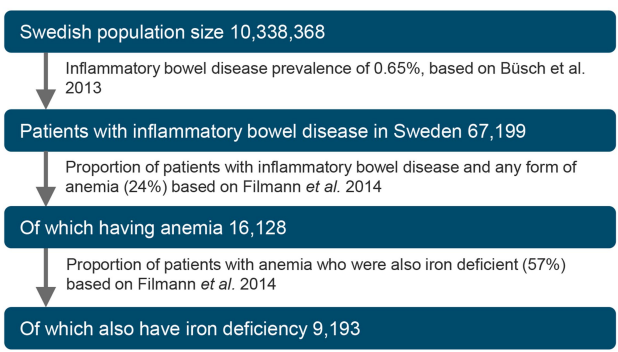

Of which also have iron deficiency 9,193

Figure 4 Patient funnel showing numbers of patients with inflammatory bowel disease and iron deficiency anemia in (A) Norway, (B) Sweden, and (C) Finland.

in the UK. ${ }^{19}$ The analysis showed that patients treated with FDI received an average of 1.14 infusions to address the iron need (compared with a modeled estimate of 1.25 infusions in the present study), while patients treated with FCM received an average of 1.56 infusions to address the iron need (compared with 1.64 infusions in the present study). ${ }^{19}$ While the absolute estimates of the numbers of infusions were slightly higher in the present analysis than in the retrospective study $(9.7 \%$ higher for FDI and $5.1 \%$ higher for FCM), the incremental number of infusions of 0.42 per patient was extremely close to the present modeled estimate of 0.39 .

As with all modeling analyses, there were also a number of limitations of the analysis. The most notable is the lack of modeling of clinical discretion; the model assumes that the calculated iron need would always be dosed in full, even in situations where a second infusion (and hence healthcare service interaction) would be

Table 2 One-Way Sensitivity Analysis Results in Finland, Sweden, and Norway Over Five Years

\begin{tabular}{|c|c|c|c|c|c|c|c|c|c|}
\hline & \multicolumn{3}{|l|}{ Finland } & \multicolumn{3}{|l|}{ Norway } & \multicolumn{3}{|c|}{ Sweden } \\
\hline & $\begin{array}{l}\text { FCM } \\
\text { Cost } \\
\text { (EUR) }\end{array}$ & $\begin{array}{l}\text { FDI } \\
\text { Cost } \\
\text { (EUR) }\end{array}$ & $\begin{array}{l}\text { Difference } \\
\text { (EUR) }\end{array}$ & $\begin{array}{l}\text { FCM } \\
\text { Cost } \\
\text { (NOK) }\end{array}$ & $\begin{array}{l}\text { FDI } \\
\text { Cost } \\
\text { (NOK) }\end{array}$ & $\begin{array}{l}\text { Difference } \\
\text { (NOK) }\end{array}$ & $\begin{array}{l}\text { FCM } \\
\text { Cost } \\
\text { (SEK) }\end{array}$ & $\begin{array}{l}\text { FDI } \\
\text { Cost } \\
\text { (SEK) }\end{array}$ & $\begin{array}{l}\text { Difference } \\
\text { (SEK) }\end{array}$ \\
\hline Base case & 3075 & 2339 & -736 & 20,767 & 15,799 & -4968 & 27,760 & 21,119 & $-664 \mid$ \\
\hline I year time horizon & 769 & 585 & -184 & 5192 & 3950 & -1242 & 6940 & 5280 & -1660 \\
\hline 3 year time horizon & 1922 & 1462 & -460 & 12,980 & 9874 & -3105 & 17,350 & 13,199 & $-4|5|$ \\
\hline $3 \%$ discount rate & 2912 & 2215 & -697 & 19,666 & $|4,96|$ & -4705 & 26,288 & 19,999 & -6289 \\
\hline Ganzoni formula & 3327 & 2200 & -1127 & 22,467 & 14,855 & -7611 & 30,032 & 19,858 & $-10,174$ \\
\hline Normal weight distribution & 3142 & 2338 & -804 & 21,219 & 15,789 & -5430 & 28,364 & 21,106 & -7259 \\
\hline Normal $\mathrm{Hb}$ distribution & 3074 & 2337 & -737 & 20,760 & 15,785 & -4975 & 27,751 & 21,101 & -6650 \\
\hline Mean bodyweight $+5 \mathrm{~kg}$ & 3261 & 2325 & -936 & 22,025 & 15,702 & -6323 & 29,442 & 20,989 & -8453 \\
\hline Mean bodyweight $-5 \mathrm{~kg}$ & 2890 & 2336 & -554 & 19,519 & 15,775 & -3745 & 26,092 & 21,086 & -5006 \\
\hline Mean $\mathrm{Hb}+\mathrm{I} g / \mathrm{dL}$ & 2955 & 2118 & -838 & 19,958 & $|4,30|$ & -5656 & 26,678 & 19,117 & -7561 \\
\hline Mean $\mathrm{Hb}-\mathrm{I} g / \mathrm{dL}$ & 3292 & 2742 & -550 & 22,236 & 18,522 & -3715 & 29,724 & 24,758 & -4965 \\
\hline 10 months between retreatments & 4612 & 3509 & -1103 & 31,151 & 23,698 & -7452 & $4 I, 640$ & 31,679 & -9962 \\
\hline 19 months between retreatment & 2711 & 2062 & -649 & 18,308 & 13,928 & -4380 & 24,473 & 18,618 & -5855 \\
\hline
\end{tabular}

Abbreviations: $\mathrm{Cl}$, confidence interval; FCM, ferric carboxymaltose; FDI, ferric derisomaltose; Hb, hemoglobin; IS, iron sucrose. 
required to administer a small dose. However, the same assumption was employed in both arms of the model and would therefore be unlikely to have been a meaningful driver of incremental outcomes. The agreement of the model's incremental projection of the number of infusions with the retrospective analysis in the UK is also encouraging with regard to the ability of the model to accurately simulate the number of infusions required with each iron formulation in routine clinical practice.

One other potential limitation was the exclusive focus of the present analysis on the number of infusions required to administer each IV iron product, and the associated costs. While the 2017 Aksan et al meta-analysis reported no significant difference in rates of hematological response between the two IV iron formulations, other differences pertaining to the relative safety of the two formulations have recently emerged. ${ }^{7}$ Most notably, recent data from the PHOSPHARE RCTs suggest that there are significant differences in the incidence of hypophosphatemia between the formulations. As a result, symptomatic hypophosphatemia was added to the warnings and precautions section of the US label for FCM in February 2020, and the European Medicines Agency Pharmacovigilance Risk Assessment Committee mandated the addition of hypophosphatemic osteomalacia to the FCM summary of product characteristics (SPC) and package leaflet by November 2020. ${ }^{3,20,21}$ Further to the warning on hypophosphatemic osteomalacia, the SPC also notes that serum phosphate should be monitored in patients who receive multiple administrations at higher doses or long-term treatment. Given this, it is likely that the present analysis was conservative in terms of the projected cost savings with FDI, as costs of phosphate monitoring and administration of exogenous phosphate were not captured. The majority of patients enrolled in PHOSPHARE had IDA associated with gynecological causes, but incidence of hypophosphatemia is not limited to this patient group; a 2019 prospective observational study by Detlie et al in patients with IBD also reported significantly and meaningfully higher incidence of all hypophosphatemia, and moderate-to-severe hypophosphatemia in patients treated with FCM. ${ }^{5}$

Furthermore, a recent indirect comparison of serious and severe hypersensitivity reactions (HSRs) after administration of IV iron found that, while rates were low regardless of the iron formulation used, the incidence was significantly high with FDI than with FCM. $^{22}$ Across the two US pivotal RCTs used for regulatory approval of FCM in the US ( $\mathrm{N}=1775)$, the incidence was $1.46 \%$ (based on 26 events), versus $0.58 \%$ with FDI based on 22 events in 3775 patients enrolled in 16 prospective studies of FDI. ${ }^{23}$ Future modeling analyses could therefore also capture the incidence of hypophosphatemia and HSRs as potential clinical and economic differentiators between the two iron formulations.

One final topical consideration is that, during the ongoing COVID-19 pandemic, reducing or ideally eliminating unnecessary patient interactions with the healthcare system has become absolutely paramount, both to reduce the risk of disease transmission and to free up hospital and healthcare professional capacity to treat patients with COVID-19. Using patient funnel-based estimates of the numbers of patients with IBD and IDA eligible for IV iron treatment across the three Nordic countries, the model projected that patients with IBD and IDA would require almost 25,000 fewer IV iron infusions over the next 5 years with FDI versus FCM. For the foreseeable future, every avoided healthcare interaction represents an opportunity to reduce patient exposure to SARS-CoV-2 and thereby potentially reduce the incidence of COVID-19, and use of FDI would therefore be preferable to FCM from an infection mitigation perspective. This is particularly important in patients with IBD, who have been shown to have a heightened fear of contracting SARS-CoV-2 in the hospital environment relative to family members of patients with IBD and healthcare workers. ${ }^{24}$

\section{Conclusions}

The present analysis showed that posological differences between the two high-dose, rapid-infusion IV iron formulations currently approved for use in the EU would be anticipated to drive differences in the number of iron infusions required to treat IDA in patients with IBD in Finland, Norway, and Sweden. The reduction in the number of infusions translated to projected cost savings of $23.9 \%$ from a national payer perspective in all three countries. Given the non-significant differences in the efficacy of the two iron formulations, and the significantly lower risk of hypophosphatemia with FDI versus FCM, FDI is both a clinically and financially prudent choice of IDA treatment in patients with IDA and IBD in the Nordics.

\section{Funding}

This manuscript was fully funded by Pharmacosmos A/S. 


\section{Disclosure}

Richard F Pollock reports grants from Pharmacosmos A/S during the conduct of the study. Gorden Muduma reports employment by Pharmacosmos A/S during the conduct of the study. The authors report no other potential conflicts of interest for this work.

\section{References}

1. Dignass AU, Gasche C, Bettenworth D, et al.; European Crohn's and Colitis Organisation. European consensus on the diagnosis and management of iron deficiency and anaemia in inflammatory bowel diseases. J Crohns Colitis. 2015;9(3):211-222. doi:10.1093/ecco-jcc /jju009

2. Kaitha S, Bashir M, Ali T. Iron deficiency anemia in inflammatory bowel disease. World J Gastrointest Pathophysiol. 2015;6(3):62-72. doi:10.4291/wjgp.v6.i3.62

3. Wolf M, Rubin J, Achebe M, et al. Effects of iron isomaltoside vs ferric carboxymaltose on hypophosphatemia in iron-deficiency anemia: two randomized clinical trials. JAMA. 2020;323(5):432-443. doi:10.1001/jama.2019.22450

4. Emrich IE, Lizzi F, Seiler-Mußler S, et al. Hypophosphatemia after high dosage iron substitution with ferric carboxymaltose (FCM) and iron isomaltoside (IM) - the randomised controlled home afers 1 trial. Blood. 2018;132(Suppl 1):3627. doi:10.1182/blood-2018-99114386

5. Detlie TE, Lindstrøm JC, Jahnsen ME, et al. Incidence of hypophosphatemia in patients with inflammatory bowel disease treated with ferric carboxymaltose or iron isomaltoside. Aliment Pharmacol Ther. 2019;50(4):397-406. doi:10.1111/apt.15386

6. Bonovas S, Fiorino G, Allocca M, et al. Intravenous versus oral iron for the treatment of anemia in inflammatory bowel disease: a systematic review and meta-analysis of randomized controlled trials. Medicine (Baltimore). 2016;95(2):e2308. doi:10.1097/MD.00 00000000002308

7. Aksan A, Işık H, Radeke HH, Dignass A, Stein J. Systematic review with network meta-analysis: comparative efficacy and tolerability of different intravenous iron formulations for the treatment of iron deficiency anaemia in patients with inflammatory bowel disease. Aliment Pharmacol Ther. 2017;45(10):1303-1318. doi:10.1111/ apt. 14043

8. Pollock RF, Muduma G. Intravenous iron treatments for iron deficiency anemia in inflammatory bowel disease: a budget impact analysis of iron isomaltoside 1000 (Monofer) in the UK. Expert Opin Drug Deliv. 2017;14(12):1439-1446. doi:10.1080/17425247.2017. 1393412

9. Pollock RF, Muduma G. An economic evaluation of iron isomaltoside 1000 versus ferric carboxymaltose in patients with inflammatory bowel disease and iron deficiency anemia in Denmark. Adv Ther. 2018;35(12):2128-2137. doi:10.1007/s12325-018-0827-5

10. Kulnigg S, Teischinger L, Dejaco C, Waldhör T, Gasche C. Rapid recurrence of IBD-associated anemia and iron deficiency after intravenous iron sucrose and erythropoietin treatment. $\mathrm{Am}$ J Gastroenterol. 2009;104(6):1460-1467. doi:10.1038/ajg.2009.114

11. Frigstad SO, Haaber A, Bajor A, et al. The NIMO Scandinavian study: a prospective observational study of iron isomaltoside treatment in patients with iron deficiency. Gastroenterol Res Pract. 2017;2017:4585164. doi:10.1155/2017/4585164
12. Hoivik ML, Moum B, Glomsaker R Inflammatory bowel disease in Norway 1999 to 2014: increasing prevalence and local geographical differences. Abstract P693 presented at the 11th Congress of ECCO European Crohn's and Colitis Organisation; 2016.

13. Büsch K, Ludvigsson JF, Ekström-Smedby K, Ekbom A, Askling J, Neovius M. Nationwide prevalence of inflammatory bowel disease in Sweden: a population-based register study. Aliment Pharmacol Ther. 2014;39(1):57-68. doi:10.1111/apt.12528

14. Manninen P, Karvonen AL, Huhtala H, Rasmussen M, Collin P. The epidemiology of inflammatory bowel diseases in Finland. Scand $J$ Gastroenterol. 2010;45(9):1063-1067. doi:10.3109/00365521.20 10.485323

15. Filmann N, Rey J, Schneeweiss S, et al. Prevalence of anemia in inflammatory bowel diseases in european countries: a systematic review and individual patient data meta-analysis. Inflamm Bowel Dis. 2014;20(5):936-945. doi:10.1097/01.MIB.0000442728.74340.fd

16. Sullivan SD, Mauskopf JA, Augustovski F, et al. Budget impact analysis-principles of good practice: report of the ISPOR 2012 budget impact analysis good practice II task force. Value Health. 2014;17 (1):5-14. doi:10.1016/j.jval.2013.08.2291

17. Kuopion Yliopistollisen Sairaalan. Kliinisten Erikoisalojen Palvelutuotteet, Suoritteeet Ja Hinnat. 2019. Available from: https:// www.psshp.fi/documents/7796350/7869509/Klinikkahinnasto+2019. pdf. Accessed July 23, 2020.

18. Helsedirektoratet. Innsatsstyrt finansiering (ISF) - regelverk. Available from: https://www.helsedirektoratet.no/tema/finansiering/ innsatsstyrt-finansiering-og-drg-systemet/innsatsstyrt-finansiering-isf. Accessed July 23, 2020.

19. Dawa Kabiru K, Maw F, Johnson M, Dhar A, Pollock R. Resource utilization and costs associated with intravenous iron infusions in patients with inflammatory bowel disease and iron deficiency anemia or hypoferritinemia: real-world evidence from the UK. Abstract and poster P1485 at United European Gastroenterology Week Virtual 2020; October 11-13, 2020.

20. American Regent, Inc. INJECTAFER ${ }^{\circledR}$ (ferric carboxymaltose injection) prescribing information. Revised February 2020. Available from: https://www.accessdata.fda.gov/drugsatfda_docs/label/2020/ 203565s009lbl.pdf. Accessed July 24, 2020.

21. European Medicines Agency Pharmacovigilance Risk Assessment Committee. Assessment Report on the PSUR(s) for iron (parenteral preparations, except for iron dextran) Annex I. Available from: https:/www.ema.europa.eu/en/documents/psusa/iron-parenteralpreparations-except-iron-dextran-cmdh-scientific-conclusionsgrounds-variation/00010236/202001_en.pdf. Accessed September 25, 2020.

22. Pollock RF, Biggar P. Indirect methods of comparison of the safety of ferric derisomaltose, iron sucrose and ferric carboxymaltose in the treatment of iron deficiency anemia. Expert Rev Hematol. 2020;13 (2):187-195. doi:10.1080/17474086.2020.1709437

23. Food and Drug Administration Center for Drug Evaluation and Research. Injectafer (ferric carboxymaltose) medical review. Available from: https://www.accessdata.fda.gov/drugsatfda_docs/ nda/2013/203565Orig1s000MedR.pdf. Accessed July 24, 2020.

24. Grunert PC, Reuken PA, Stallhofer J, Teich N, Stallmach A. Inflammatory bowel disease in the COVID-19 pandemic - the patients' perspective. J Crohns Colitis. 2020. doi:10.1093/ecco-jcc /jjaa126 


\section{Publish your work in this journal}

ClinicoEconomics and Outcomes Research is an international, peerreviewed open-access journal focusing on Health Technology Assessment, Pharmacoeconomics and Outcomes Research in the areas of diagnosis, medical devices, and clinical, surgical and pharmacological intervention. The economic impact of health policy and health systems organization also constitute important areas of coverage. The manuscript management system is completely online and includes a very quick and fair peer-review system, which is all easy to use. Visit http://www.dovepress.com/testimonials.php to read real quotes from published authors. 